\title{
The Research on Mobile Application Oriented Language Teaching Database: Design and Development
}

\author{
Min JIANG ${ }^{1, a}$ \\ ${ }^{1}$ International Cultural Exchange College of Xinjiang University, Urumqi 830046, China \\ aminjiang@126.com
}

Keywords: Mobile Application; Language Teaching Database; Teaching Resource

\begin{abstract}
This mobile learning based on mobile terminals and wireless communication networks anywhere, anytime learning mode, to further expand the digital learning. Carry out effective mobile learning, it requires extensive learning resources in line with the law of mobile learning and mobile device features. From the nature of mobile learning, characteristics of the concept of mobile learning were defined, analyzed the connotation of learning resources and mobile learning resources for mobile learning resource classification, discusses the basic principles of mobile learning resources development, explore mobile learning the basic pattern of resource development, providing reference value for the design and development of mobile learning resources.
\end{abstract}

\section{Introduction}

With computer technology, the rapid development of network technology and mobile communication technology, mobile phone, PDA and other popular portable increasing popularity of mobile devices [1]. Changes in technology and changes in cultural concepts of mobile IT access conditions for people's daily life had a profound impact, this effect will inevitably affect the way people learn and study habits. Mobile learning has been used as a new way of learning quietly into people's daily learning.

This mobile learning based on mobile terminals and wireless communication networks anywhere, anytime learning mode, to further expand the digital learning. Carry out effective mobile learning, it requires extensive learning resources in line with the law of mobile learning and mobile device features [2]. Learning Resources is to carry out the first element of mobile learning.

Therefore, the learner to mobile phones as a learning tool, but also depends on learning support institutions to provide rich, personalized learning content resources. The development of mobile phones based on learning resources is a necessary condition to carry mobile learning, only those with a rich, personalized mobile learning content resources to make people any time, any place, good wishes on-demand learning possible. Based on this, combined with the characteristics of mobile learning to explore the principles of learning resources developed by cell phone, by computer multimedia teaching software development process analysis, exploring the design and development of mobile learning resource model.

\section{Mobile development technology}

Mobile technology because of its open source and powerful features make a lot of attention [3]. Officially listed in a few years, a wide range of mobile operating systems, to become the world's most popular mobile operating system. Now, mobile phones are widely used to provide a convenient means of mobile Internet not only on smart phones, can also be used for mobile Internet terminals, and other handheld devices [4]. Now the mobile phone market, many brands are using mobile phone system, launched its own mobile phone, China Mobile and China Unicom and other operators to develop mobile-based operating platforms. Mobile systems in people's everyday lives has always played an important role. Mobile applications are composed of loose affinity list of applications, components, and use, the application list describes each component interaction 
between them, and metadata applications. Mobile operating system complete API and open nature, as shown in figure 1 .

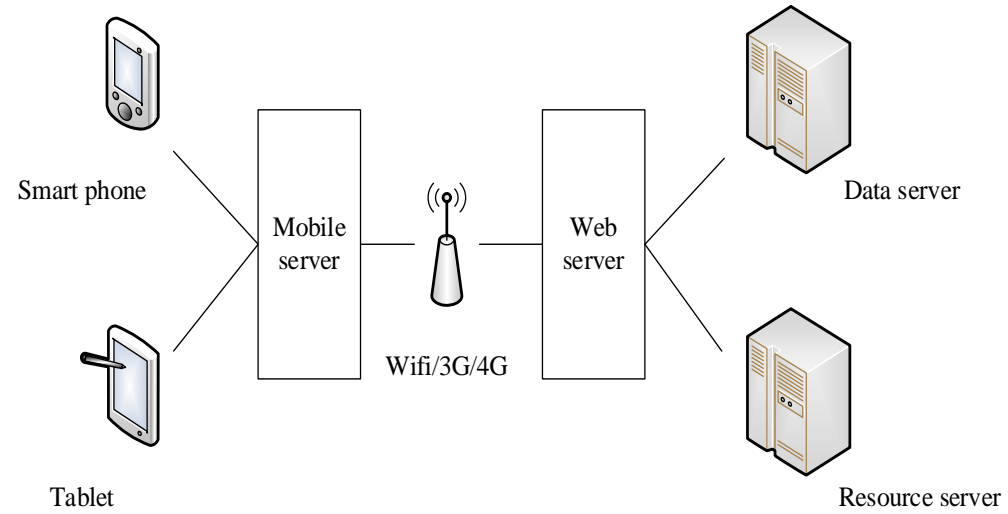

Figure 1. Mobile system framework

Mobile system customers include portable smartphones tablet PCs and mobile devices, users access their learning and other learning programs and mobile devices-related operations. Mobile Learning System server consists of two parts, database servers and server resources [5]. The main function of the database server is to store information related to the student's personal, legal and responsible for the correctness of validation and feedback users to submit personal information. Therefore, curriculum resources (hypertext, pictures, animation, streaming media, etc.) and on-line interactive information processing, including student asked the teacher to answer questions, and so on.

\section{Functional analysis of language teaching resource library}

The platform is mainly aimed at two types of users: teachers and students, teachers, locally or remotely via a PC landing platform for the production and distribution study website WAP class, organize and participate in learning activities and learning activities adjustment, and the student feedback WAP site resources to make changes. Students through landing WAP site customize explorer learning, with other students and teachers to discuss collaborative learning style by moving the forum when you have questions about a certain issue, or through the website built-in mobile Internet search function to find more theme-related information, in order to deepen the understanding of the depth and breadth of knowledge.

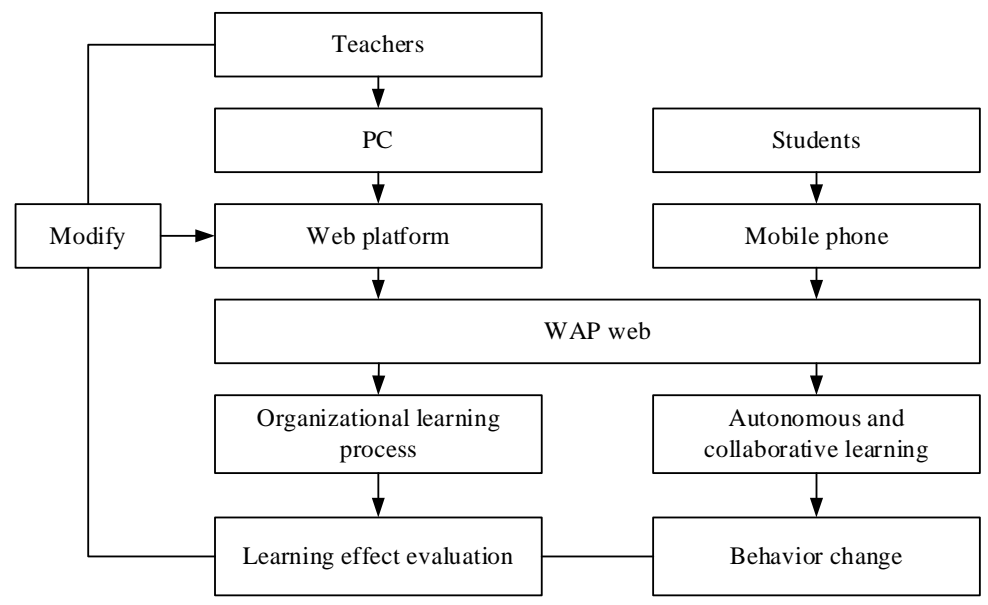

Figure 2. The functional structure of language teaching resource library

Therefore, in order to meet the needs of teachers and students of the above, language teaching resource library should include two meanings: First production release of Web-based teacher WAP site platform where teachers can input text by operation similar to Word, you can insert pictures production and distribution WAP site without any programming knowledge to understand. In 
addition, teachers can also be initiated in this online survey, statistics and analysis learner feedback on WAP sites, web resources in order to facilitate changes, the platform is also a place for analysis and statistics learner content information. The second layer of meaning is a teacher through a Web platform production release of WAP sites, student learning activities are mainly carried out in this function diagram shown in figure 2.

Because this system is based on experimental studies of mobile learning platform, and its main objective is to design and develop a simple and reliable mobile learning platform, the system design process following the development of the main principles, the principle of principle feasibility, practicality and safety ${ }^{\text {i? }}$ ? The system is designed to take full advantage of existing curriculum resources, to ensure the safety of the premise, communications, design, so that the hair of a real-time, fast, easy to maintain, extend and update mobile learning platform, so teachers and students can at any time, anywhere for their knowledge and information, to achieve a real sense of self-learning. Mobile learning platform through requirements analysis, design and implementation platform design and implementation in three stages, design and implementation of the platform is two parallel stages, the flow chart shown in figure 3.

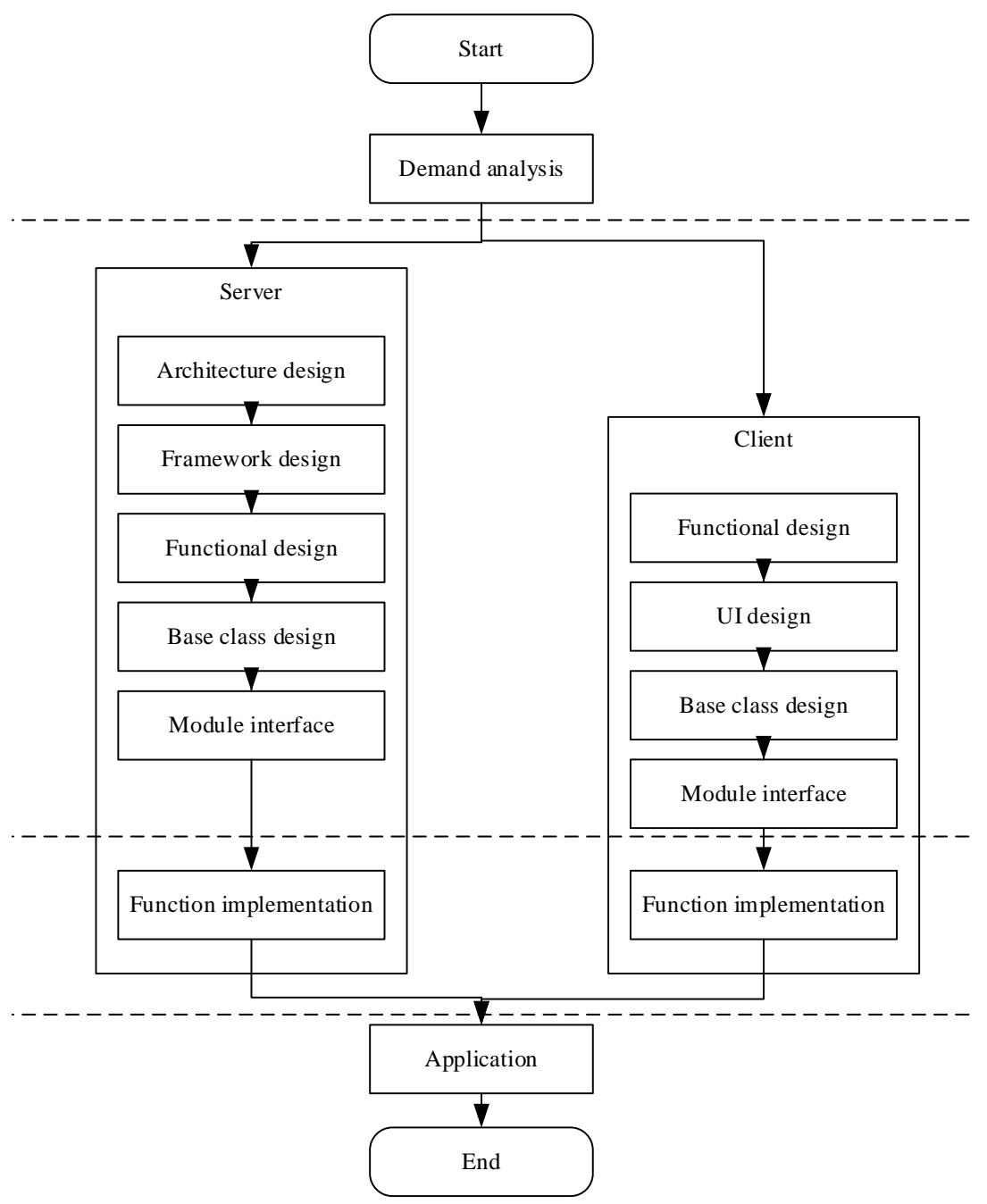

Figure 3. The design process of mobile teaching platform

Design of mobile learning platform includes server and client design. Server-side design of the overall design includes architectural design, structural design and functional design, the base class design, module design, customer design, including functional design, UI design, the base class design, module design. On the basis of design, this chapter in the server class design and module design, the design of the customer concern is the functional design and user interface design. 


\section{Language teaching resource library technology architecture}

The system is based on Web technology J2EE development approach. The overall architecture of the teaching system designed in detail herein. Meanwhile, the main business object system (administrators, teachers and students) were classified design major operational role, but also each function module specific ideas, and activity diagrams. In addition, we also need to design appropriate main target database tables, modeling design and analysis. The language teaching resource library architecture is shown in figure 4.

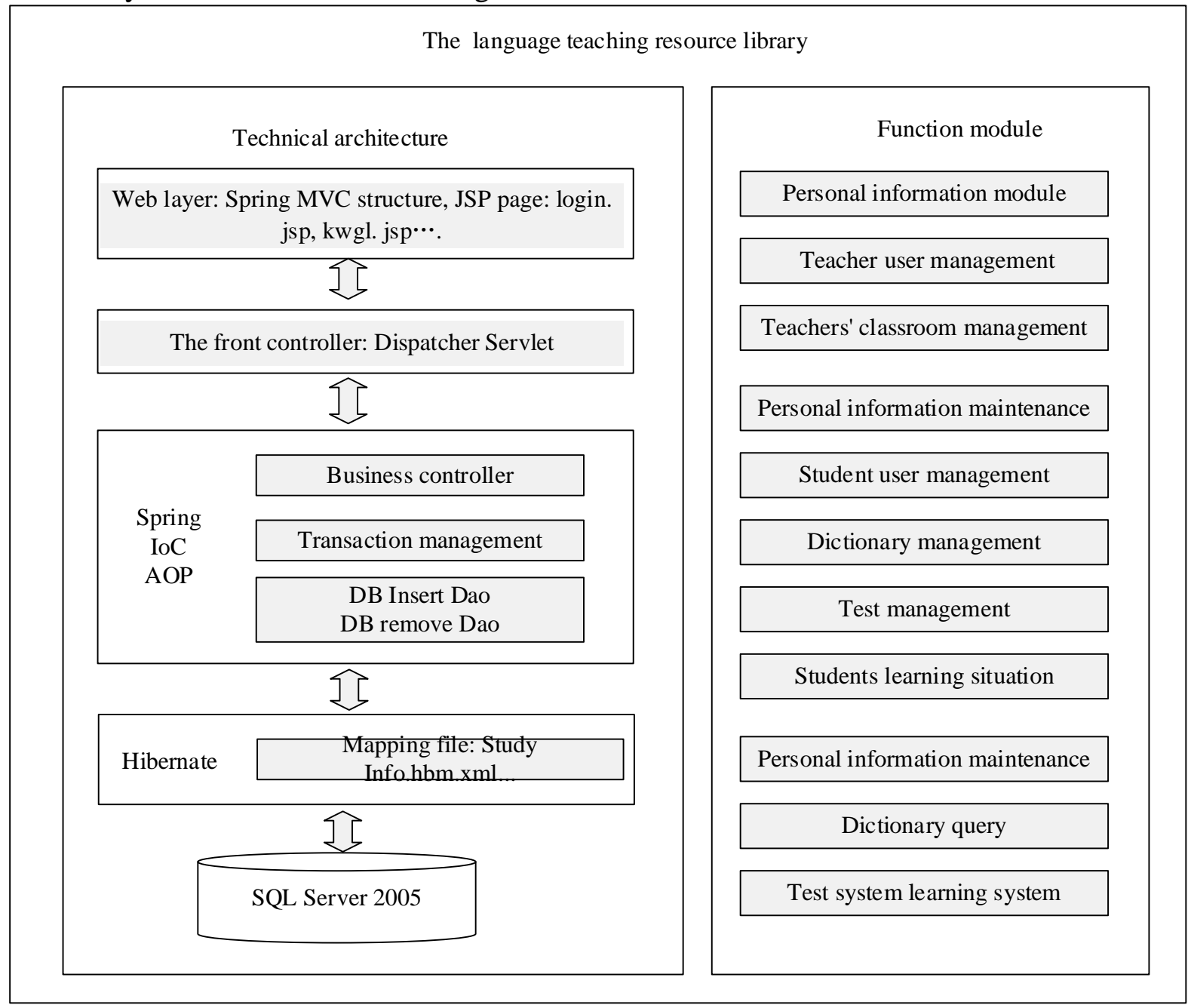

Figure 4. The architecture of the language teaching resource library

Construction of network-assisted teaching system in teaching infrastructure, in addition to net, ASP, ADO, SQLserver2000 enterprise technology, but also need to integrate network communication technology, network multimedia database technology, network programming technology, network technology, virtual reality and artificial intelligence technology personalized, interactive and practice of ideological and political education network platform, an important factor in the overall design of the overall design to achieve good educational results.

\section{Conclusion}

Effective mobile teaching requires extensive teaching resources in line with the law of mobile teaching and mobile device features. Teaching resources are an important safeguard in mobile teaching. This study further to introduce people to the characteristics and application of mobile teaching on the basis of the existing research on mobile teaching, to help raise awareness of this new way of teaching, changing the concept of teaching to accept and actively use this mobile 
teaching. This study attempts to build mobile teaching resources to develop basic model to provide reference for the design and development of mobile teaching resources.

\section{Reference}

[1] Sykes J M, Oskoz A, Thorne S L. Web 2.0, synthetic immersive environments, and mobile resources for language education[J]. Calico Journal, 2013, 25(3): 528-546.

[2] Tillmann N, Moskal M, de Halleux J, et al. The future of teaching programming is on mobile devices[C]//Proceedings of the 17th ACM annual conference on Innovation and technology in computer science education. ACM, 2012: 156-161.

[3] Kranz M, Murmann L, Michahelles F. Research in the large: Challenges for large-scale mobile application research-a case study about NFC adoption using gamification via an app store[J]. International Journal of Mobile Human Computer Interaction (IJMHCI), 2013, 5(1): 45-61.

[4] Ng S C, Lui A K, Ngao S H. An Interactive Mobile Learning Platform for Teaching and Learning Chinese Language in Secondary School Environment[M]//Knowledge Sharing through Technology. Springer Berlin Heidelberg, 2013: 135-147.

[5] Hsu L. English as a foreign language learners' perception of mobile assisted language learning: a cross-national study[J]. Computer Assisted Language Learning, 2013, 26(3): 197-213. 